\title{
Covid-19 and the Healthcare System in China
}

\author{
Ulrike Reisach $^{1^{*}}$ and Yangping Zhou ${ }^{2}$ \\ ${ }^{1}$ Information Management Department, Neu-UIm University of Applied Sciences (HNU), Germany \\ ${ }^{2}$ Graduated from the Department of Psychology and Pedagogics, Ludwig Maximilians University Munich (LMU), Germany
}

\begin{abstract}
China is known as a high-context culture, which is why our paper analyses the Covid-19 crisis in the broader context of Policy, Economy, Society, Technology, Environment and Law (PESTEL). Following this model, the challenges and influencing factors on the pandemics are being examined. While doing so, we focus on the health-related aspects such as (P) health policy, (E) health-economy, (S) societal issues, including living conditions and culture, $(\mathrm{T})$ technology, as well as electronic health records, testing, and applications (apps), (E) environment and climate, and (L) the health insurances. Ours is not a medical analysis, but is intended to provide insights which might enlighten how and why the virus spread so fast in Hubei Province in China, whose capital is Wuhan. Applying the PESTEL model, we show how institutional settings and crisis-management approaches were adapted to the challenges before and during the crisis.
\end{abstract}

\section{Keywords}

Covid-19, Healthcare, China, Hospital, Culture

\section{Introduction}

China is the most populous country in the world. The health care system of this country therefore influences how more than 17 percent of the world's population live. Since China was hit by the COVID-19 virus, they have become a testing laboratory for the world. Initially, a lack of detailed knowledge led to insufficient information and action, followed by fear, anger and chaos. But the Chinese finally achieved fast progress in dealing with the related issues and were able to forward their findings to the world. Trial and error in the initial phase was replaced by adaptability and pragmatism and a joint effort of governance, scientists, businesses and millions of people who endured a minimum of eight weeks of confinement.

"The fear of getting sick is the biggest concern of the people in China" [1]. Part of this is historical: The barefoot doctors during Mao Zedong's time were replaced by community health centers, and traditional medicine was combined with Western approaches. The main advancement of Western medicine was the knowledge of infectious diseases and how to combat them [2]. The scientific approaches in diagnosis and treatments were imported by Western scholars in the early $20^{\text {th }}$ century. Modern China followed this development and a close international co-operation and exchange between Chinese and Western doctors started. However, the issue of uneven quality and resources of hospital and medical staff across the country, as well as the expensive medical fees for people especially those living in the countryside make them very concerned that it would be "better not to get sick".

\section{Methods of Knowledge Acquisition}

Based on our experience in China-related research in political, economic and social sciences, we tried to find out whether the development of the crisis has certain system-specific traits. We built on our previous work about the Chinese health care system [3] which allowed us to learn from physicians, hospital managers, health-industries and patients. We have now researched the latest data available from national statistical offices, health ministries, official government websites and international organizations, journals and newspapers, being well aware that the data are not necessarily accurate and comparable due to different definitions, counting modes and data provision. For more detailed information, we have relied on residents and scholars who spent the Corona-time in China were contributing (see acknowledgements). Regarding the "hot spot" of the crisis, we received information from citizens of Wuhan and compared those pieces of information with the respective data and reports.

\footnotetext{
*Corresponding author: Prof. Ulrike Reisach, Ph.D, Information Management Department, Neu-Ulm University of Applied Sciences (HNU), Wileystr 1, D- 89231 Neu-UIm, Germany

Received Date: April 27, 2020

Accepted: May 30, 2020

Published online: June 01, 2020

Citation: Reisach U, Zhou Y (2020) Covid-19 and the Healthcare System in China. Arch Fam Med Gen Pract 5(1):98-108
} 


\section{Factors which (might) influence the Corona crisis in China}

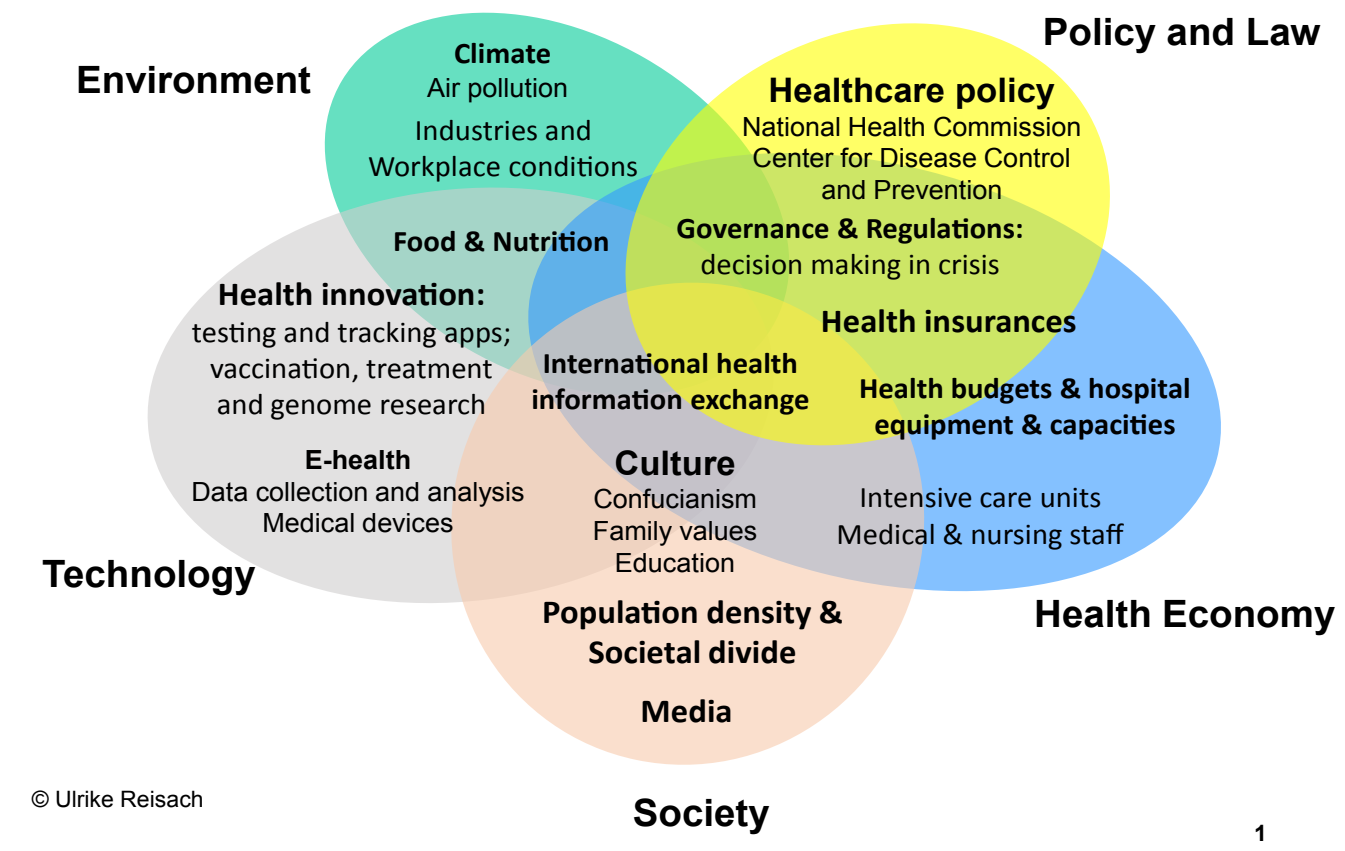

Figure 1: Factors which (might) influence the Corona crisis in China. (Read Clockwise).

We examine here the main influencing factors by following the PESTEL scheme [4], a strategic analytical tool which we use to analyze the potential impact of the framework conditions on the Corona crisis. Each of the PESTEL fields represents one or two research questions (RQ) which are answered by a situation analysis before and during the crisis (Figure 1).

\section{The PESTEL Analysis}

\section{The political background}

$R Q$ : Could specific political factors influence the spread of the Corona virus in China?

The People's Republic of China is a socialist republic run by the Communist Party of China, headed by the current General Secretary Xi Jinping. Some of the major values of the governance in China are long-term thinking and planning, a strong will to live in harmony and related to Confucian hierarchies, respect and care for the elders, continuous adaption to changes (floating like the water, bowing like a bamboo), education, continuous learning and striving for excellence.

The state is the owner and operator of most hospitals and health insurance companies. In recent decades, China has been able to drive forward the expansion of its health care system through higher investments and spending, so that general key figures on the standard of medical care have improved considerably.

The Chinese government has been striving to improve the efficiency of the administration and reduce the complexity of the whole system, including the healthcare system. After loosening the one child-policy, the former Chinese National Health and Family Planning Commission was dissolved In
March 2018 and integrated into the new National Health Commission (NHC), as part of State Council. The NHC comprises more functions and established a new concept of "Great Hygienics and Great Healthcare". It transformed the center of treatment into the center of people's health, and made policies on medicine and healthcare system reform, dealing with aging problems in the country, and promoting the combination of treatment and nursing [5]. The Chinese Center for Disease Control and Prevention (CCDCP) is one of several organizations under NHC. Another function of NHC is to supervise hospitals. In each regional level, province, city, town there is a Health Commission organization which supports the management of local hospitals.

Those institutions would have been responsible for dealing with the crisis, but they were preoccupated with seemingly important official tasks which had an unlucky time co-incidence with their annual Province People's Congresses from $7^{\text {th }}$ to $10^{\text {th }}$ January and the Chinese New Year celebrations. By the middle of January 2020, CCDCP issued a press release that the risk of transmission among people was very low [6]. This was a misjudgment, as all know now, and led to a delayed reaction and shut down. Multiple levels of response and hierarchical responsibility stretched the process, which resulted in less transparency. On $20^{\text {th }}$ January it was officially stated that the novel virus was transmitted to the people and an order from Mr. Xi made sure that the official bureaucracy leapt into action [6]. To lockdown a city would surely create chaos and panic. It was until $23^{\text {rd }}$ January that the local government decided to close the city. At that time around five million people already left Wuhan for the Chinese New Year, as mentioned by Wuhan's mayor Zhou Xianwang on $26^{\text {th }}$ January. This was criticized later by the public that it was too late to do this ac- 
tion, because some of those five million people disseminated the virus across China.

Result: Although the health system reform lead to improvements, issues such as official duties and bureaucratic processes delayed the appropriate decisions which would have been necessary at the beginning of the epidemic. Decision-making in uncertain situation is always difficult, but even more so in complex hierarches and unclear priorities: The government of Wuhan had trouble balancing the trade-off between local interests in harmonious festivities and announcing the necessary measurements to avoid the virus from spreading.

\section{The economics of the health care system}

\section{The healthcare system in China and its performance during the crisis:}

RQ: Did specific health related resources and capacities have influence on the containment of the Corona virus in China?

The idea of a "socialist market economy", introduced in 1978, was transferred to a kind of "state capitalism": Huge and subsidized state-owned companies and state-owned hospitals, combined with private institutions and a huge internal competition. Measured in terms of population size, the number of hospitals in China is comparatively small, at around 34,000 , comprising military, educational and public hospitals, and, in the major cities, a growing number of private clinics.

According to the Hospital Classification Management Standard [7], hospitals in China are generally classified into 3 levels based on the criteria such as hospital scale, scientific research, talented force, medical hardware equipment. Taking one criterion of hospital scale as example, the first level, which is the lowest, hospitals have $20-99$ beds. They are primary hospitals that directly provide medical and health care services to the community nearby. The second level with between 100 and 499 beds, they provide medical and health services across several communities. The third level which is the highest level has more than 500 beds and provides ser- vice across regions, provinces and cities. Each level is further divided into A, B, and C based on the quality. "Level 3" hospitals can treat serious diseases such as Covid-19.

According to this classification, the best hospitals are either military hospitals or joint ventures with international partners. Examples for the educational level 3 hospitals are those directly connected to top universities like Beijing University ("Beida") or Qinghua. In Shanghai, the Jiao Tong University alone has four affiliated hospitals. The good reputation of the universities and that of the affiliated hospitals reinforce each other, and these are also the institutions that are granted the largest budget for personnel and equipment by the central or city government. When people are seriously ill, they have to go to a level 3 hospital. Normally short-staffed community clinics handle light illness (cold, infection, injury, etc.), vaccinations or the occasional massage and intravenous drip to rehydrate the old people in the neighborhood. Depending on the size of the city and the category of hospital, hygiene standards in China range from very good (level 3 hospitals) to sometimes considerably below Western standards in municipal hospitals of the primary sector in more remote regions [7].

The table below shows the latest respective data and compares them with Germany, which has one of the best healthcare systems in Europe and succeeded to contain the virus relatively fast and with low numbers of victims. According to the OECD [8] Germany has the highest number of acute care hospital beds and intensive care beds per 1000 population, when compared with the USA and other European states (Table 1). Such a comparison should consider that China has 18 times more inhabitants and covers 27 times more land than Germany. Germany also has a time advantage: They developed their "social market economy" since 1949, while China started with their "socialist market economy" in 1979.

In the countryside, the situation is worse than these figures suggest: About 70 percent of medical resources are concentrated in the cities. However, the majority of the population lives in rural areas and often has to travel long dis-

Table 1: Chinese hospitals by the numbers - a comparison with Germany (own representation).

\begin{tabular}{|l|l|l|}
\hline Criteria & China (2018, 2019) & Germany (2017) \\
\hline Number of inhabitants (total) & $1.4 \mathrm{Bn}$. & 82.9 Mio $^{*}$ \\
\hline Number of hospitals (total) & 34,000 & 3,084 \\
\hline Number of beds (total) & 6.97 Mio. & 661,448 \\
\hline Number of beds per 1,000 inhabitants & 5.0 & 8.0 \\
\hline Bed occupancy & $84.2 \%$ & $77.8 \%$ \\
\hline Average length of hospitalization & 9.3 Days & 7.5 \\
\hline Days Number of doctors (total) & $3,010,040$ & $351,195^{*}$ \\
\hline Number of doctors per 1,000 inhabitants & 2.6 & 4.3 \\
\hline Number of nursing staff & $4,430,000$ & $1,069,000$ \\
\hline Number of nursing staff per 1,000 inhabitants & 3.2 & 13.0 \\
\hline
\end{tabular}

Data for China: From National Bureau of Statistics of China (NBS). Data for Germany: Numbers with * are from Eurostat, and the rest are from OECD Data [52-56]. 
tances to receive qualified medical care. There are usually no alternatives. The government is making efforts to improve the standard of health care in the provinces. This is not always achieved immediately, as it can take time to implement central guidelines in the provinces and municipalities. Already the Confucian philosopher Xunzi (Xun Kuang or "Master Xun") said aptly: "It is people and not laws on which order is based".

Wuhan, a city with 14 million inhabitants, had three main hospitals in the city center which were designated for infectious diseases and had Intensive Care Units (ICU):

- Jinyintan Hospital with 5 doctors in ICU,

- Hankou Hospital with 4 doctors in ICU and,

- Wuhan Lung Hospital with 5 doctors in ICU.

One of the hospitals did not have a negative pressure room which is used to contain airborne contaminants within the room. This means that they could not make sure in the other two that pathogens would spread to other rooms. The lack of capacities meant that those hospitals were overwhelmed by patients and closed off. Families needed to look for help elsewhere, some searched for hours, together with their sick relative. This stole valuable time because the treatment needs to be given as fast as possible to keep the lung function. To find no help for sick relatives is a big stress for the family.

After the president's call for action after $20^{\text {th }}$ January, very soon six other hospitals in the area took covid-19 patients. And two famous square cabin hospitals Huo Shen Shan and Lei Shen Shan were built in 10 days and more equipment was provided. Later on, the beds in all major hospitals in Wuhan were freed up for the treatment of critically ill patients, and the square cabin hospitals were used for the treatment of mild patients. For the bigger area around Wuhan, the figures of April 2020 indicate a sum of 61 level 3 hospitals, 27 of whose are level 3A [9], but those figures probably include all newly installed care facilities and could not be confirmed.

Results: The enlarged healthcare capacities show the progress achieved but, at the same time, it becomes clear that the Chinese healthcare system needs to improve further in order to reach conditions such as in South Korea or Germany and to shield pandemics.

\section{Hospital structures and procedures:}

$R Q:$ Do hospital structures and procedures impact the spreading of Covid-19?

Normally processes in Chinese hospitals are very efficient and effective in view of the high number of patients. This applies to findings, diagnosis and therapy. Nevertheless, even well-equipped hospitals in China can have problems with transmittable diseases. Hospital outpatient and intensive care units are designed as large halls, single treatment rooms or double rooms are rare [3]. If the outpatient clinic is not full, so the widespread opinion, then the hospital cannot be good. In the admission area, there are counters of health insurance companies to make sure the hospital services are payed in advance. Since the treatment steps are billed in- dividually, patients or their accompanying persons (usually family members) queue up several times at different queues for payment, for admission to the outpatient clinic, for examinations, for picking up medication. Even in normal times there is a lot of crowding and hardly any distance (adapted from [10]). This conceptual structure of hospitals was problematic at the beginning of the crisis: "Hospitals ... showed up as clusters in the early days as patients were spreading it in the waiting rooms" [11].

The closure of Wuhan and two nearby cities on January $23^{\text {rd }}$ helped to slow the spread of the epidemic to other parts of China, but it did not really stop the spread of the virus in Wuhan. On the contrary, according to local doctors and patients, the virus continued to spread among family members who stayed at home, largely because the hospitals were overwhelmed and unable to test and treat all patients. What really reversed the situation in Wuhan was the more active and systematic isolation mechanism adopted after February 2 [12]: Suspected or mild patients, even healthy people who had close contact with confirmed cases were sent to the shelter hospital. Hundreds of hotels, schools and other places were transformed into isolation points and two new hospitals, and 14 square cabin hospitals were established in public buildings.

Results: China's hospitals are hierarchically structured along their quality. State-owned top hospitals handle masses of patients. But some of their internal processes of payment admittance are suboptimal for infectious diseases: long waiting times in front of the pay stations, full outpatient clinics, lack of distance. The measurements taken such as free admittance to hospitals and online payment could be a model for the future, too.

\section{Medical staff:}

$R Q:$ Does China have sufficient medical staff resources to support corona patients?

The official doctor density in Table 1 is 26 doctors per 10,000 inhabitants across China. In rural areas there is about 18 doctors per 10,000 inhabitants, in the city there are 40 $[13,14]$. Because there are different certificates and qualifications, we only count Chinese doctors with qualified certificates that allow them to treat patient independently.

Chinese doctors generally have good professional qualifications and complete a high workload, but their salaries are relatively low, compared to companies [3]. Doctors work as experts in a very specific field within their discipline. This allows them to gain a lot of experience/routine and speeds up the processes, which is necessary in view of the high number of patients, e.g. in outpatient clinics. The specialization is also common in Western clinics and all those who are no such specialization need to learn fast how to deal with issues of the respiratory system and with lung machines.

The chronic shortage of personnel is more serious for nurses than for doctors [10]. Nurses are overburdened in both the outpatient and inpatient sectors. As a result, nursing workers getting popular in many areas to take care of the patients besides nurses and the relatives of the patients. They 
are employed by patients (through a housekeeping company) or by their family members to assist nurses to provide daily care and assistance to patients. Those subsidiary nurses explain the low number of regular nurses as visible in Table 1 , last line. The fact that only richer people can afford such an additional nurse, makes clear that the health system in China does not treat patients equally. Poorer patients are in rooms with many other patients, and family members accompany them to replace the lack of expensive private nurses.

Medical staff especially in Wuhan faced difficulties such as heavy work tasks, high risk of infection, limited working and rest conditions, and high psychological pressure. Therefore, on February 11, a notice was issued by the State Council to improve the working conditions of front-line medical staff and to care about the physical and mental health of medical staff. They should e.g. get sufficient sleeping and break time, adequate protection materials, psychotherapy for those who mentally suffered, a higher salary and allowance, promotion to higher positions, awards and recognitions [15].

Results: At the beginning of the spreading, there was a severe shortage of medical personnel and some got infected as well. Later the country mobilized a medical team of more than 40,000 people from different cities to Wuhan and improved the working conditions for doctors and nurses.

\section{Society}

$R Q:$ Could specific societal factors influence the spread of infectious diseases in China?

Societal divide: The successful fight against hunger in China is one of the country's great achievements and many living conditions in China have developed positively since 1980. Nevertheless, the gap between rich and poor is therefore now much wider in China than in any other Asian country. The Gini coefficient, which measures the inequality of a society on a scale of 0 to 1 , was estimated at 0.5 in 2018 [16]. This means that wealth in China is distributed more unequally than in the USA and Russia, for example.

Rapid growth led to progressive urbanization and industrialization and a high level of intra-Chinese migration. More than half of China's population now lives in megacities. In addition to the migrants' mostly low wages, many of them have no protection through health insurance. Living conditions in Megacities may cause health issues: Through the high population density and the crowds in the metro stations, a virus can spread easily. Since apartments are expensive, lesser wealthy families live closely together, often three generations together. During the confinement, if one person was infected, the virus could easily spread among the whole family.

The epidemic turned out to be a huge risk for migrant workers who bought property with loans, because they cannot pay back because of the complete lock down of the city [17]. The dictum of the Chinese reformer Deng Xiaoping, according to which some should first become rich and the others should follow, was heavily strained by the luxury consumption of the upper class.
Because of its central location, Wuhan it is the main distribution point in central China for the Yangtse river, railway, road and other transport. In 2019, Wuhan was raked as China's $9^{\text {th }}$ best performing city by the Milken Institute [18]. Through the Belt and Road Initiative, Wuhan has attracted many more businesses from all over the world and 230 of the Fortune Global 500 companies had invested there: automotive manufacturers and their suppliers, chip-making and biomedicine companies.

\section{Cultural factors:}

Confucianism: In Confucianism the order of nature is seen as parallel to the order of society. The fight against diseases is similar to a war, a similar vocabulary is used [2]. Order is restored through the cultivation of the human being, in the case of the sick, for example, through special food and behavior in accordance with the rules.

This might be one of the explanations why the citizens followed the relatively strict restrictions which were controlled by Communist Party guards during the containment phase. Another factor is the tradition of patriarchal authority [19] and hierarchy: Top down-decisions are common and subordinates have very little freedom of decision [20], neither about the design of the system nor about their own area of responsibility, and in some cases not even about important questions of their own lives. They are dependent on guidelines and higher ranks, e.g. the state administration or parents and rarely question them. Especially in crisis situations, people won't dare to contradict.

Adaptive behavior is a consequence of collectivism and living in communities [21]. Asians tend to wear face masks routinely when sick or traveling or during the flu season, to protect themselves but also others. Face masks were made compulsory at the end of January 2020 and people could get arrested for not wearing them. Health officials went from door to door to inquire about health issues and take the temperature. These measures are not considered intrusive, people rather feel secure by it.

The Health Commission is a planner and fatherly admonisher in matters of health: Education programs are designed to protect the population from the most common diseases. Through using modern formats (television, schools, universities, videos at railway stations, social media campaigns), such programs can be managed quite successfully through the state media.

Teaching and continuous learning are part of Confucian tradition. During the crisis, digital teaching of schools and universities was an important tool to keep the young generation learning. China already had huge capacities for digital interaction but increased those during the confinement time to make sure that education would continue. Teachers were supported through MOOCs and encouraged to offer comprehensive online services. The most popular software used for distance learning and teaching in China was Dingding or Tengcent. Especially Dingding, almost 120 million [22], half of the country's students and pupils in March were using this platform where one can take part in live classes, watch recorded 
classes. This software also offers home school management, for instance, notification from teachers, contact book, presence of participation, homework assignment and other functions. Manifold state media supported those initiatives and the government used that opportunity to emphasize the national cohesion.

Traditional Medicine and habits: The modern form of Traditional Chinese Medicine (TCM, zhongyi, literally: Chinese medicine) has little to do with the dubitable and sometimes dangerous eating and healing practices that were common among miracle healers in the Chinese Middle Ages [23]. For example, since blocked bronchus is a problem with all kinds of flues and Covid-19 as well, TCM methods such as moxibustion and acupuncture were used to clean the respiratory tubes.

The results of the autopsies of corona patients were published during a news conference in Beijing on March 24, 2020 by Wang Guiqiang, the head of the Department of Infectious Diseases at Peking University First Hospital. Their research revealed that “... patients' immune systems have also been damaged, with a significant drop in immune cells, which could be an important factor for their death. ... The decrease of immunity also increased the possibility of bacterial and fungal infections, and patients in critical condition often suffer multiple infections" [17].

Smoking and antibiotics might influence the immune system and the general condition related to Covid-19: A particularly dangerous type of lung disease affects about 90 percent of smokers. The figures on smoking in China do not fully support an extraordinary risk: On average, $26.6 \%$ of the population above 15 years smokes. Around half of the male (50.5\%) and only $2.1 \%$ female are smokers [24]. The smoking rate in cities $(25.1 \%)$ and countryside $(28.9 \%)$ is close to each other. Antibiotics are often used for curing winter flues in China and can easily be obtained without a prescription in community pharmacies in urban China [25]. While antibiotics work well for bacteria, they do not work for a virus and can weaken the immune system. Antibiotics are not useful for preventing SARS-CoV-2 but could help in case of bacterial co-infections [26].

A general improvement of the immune system through healthy eating. In the outbreak period, Chinese medicine doctors have been suggesting to use special food, herbs, and teas to enhance the immune systems and prevent from the corona virus [27].

Food culture is broad and deep in the society. Rooted from the Chinese traditional medicine, people think certain food have special nutrition and medical effects. People like to try new and exotic food: Wild animals like bats are eaten; this is assumed to have caused the virus to jump from animal to humans. Street-food is cheap and common, hygienic controls are scarce, spitting and eating with the fingers is frequent. Collectivism means eating together, very often with chop sticks from joint plates. One of the huge gatherings for a joint dinner took place on January $18^{\text {th }}$ : Following a 20 year's tradition, Wuhan celebrated a massive annual potluck banquet for 40,000 families from a city district. This was a party where people brought the dish they prepared, watching and eating and talking to each other. In this critical period, such kind of party was not stopped by the local leaders and then was later criticized of not taking the virus seriously [28].

Health related values: The perception and assessment of what is normal, what is (health-) endangering and what is illness and suffering is influenced by what one has heard and seen from childhood. The definitions of health and illness and the communication about the respective condition are largely culturally shared behavioral patterns.

In Chinese culture long life is valued and a family with old people is respected. The possibility of the death of a seriously ill patient is not openly addressed and often repressed in thought. Every effort is made to prolong life; families spend several years' income on this and get into debt. It is considered the duty of the children to ensure the long life of the elders and it is forbidden to talk about death. For most Chinese death is not a topic one would mention even in times of sickness.

These contrasts to the practice in Germany: Everyone can decide in a so-called patient decree, which kinds of treatments they want or don't want in case of severe health issues. The patient is the sovereign and relatives and doctors need to follow this will. In the majority of cases, the intensive therapy is terminated when it no longer appears useful. As a quote of Dr. med. Altiok, senior physician at the intensive care unit in Aachen, Germany shows: "If it becomes apparent that the previously agreed therapy goal can no longer be achieved, we will change it in consultation with the relatives" [29]. This procedure can turn out to be a live savior for other patients, who are not yet terminal ill, during the Corona crisis: Those can get the necessary intensive care and might boost he numbers of recoveries.

In Germany, hospital rooms have one to four beds, very rarely more. A two or three bed room is very common. If the operation is over and the patients are back from the wake-up room, relatives may visit during certain times, usually for a short time during the afternoon. Food is provided by the hospital canteen and carried in the rooms and body care is given by professional nurses. In China, relatives often stay with the sick person and bring food, and sleep beside the bed on the floor or on a chair. Being so close with relatives of several patients staying for hours or overnight, the spread of the new virus was inevitable.

Results: Societal and family related values seem to have influenced the spread of the Corona virus. The population density and wealth disparity contributed to the fast spread of the virus. Fast decision making as well as rational considerations regarding live, health, eating, hygiene and even death can help avoiding further contamination and high numbers of victims.

\section{Technology}

RQ1: Could specific technological factors influence the spread of infectious diseases in China?

The electronic health record (EHR) emerged in 2003 because of SARS with a rapid rise. Since 2010, the Chinese Min- 
istry of Health has been attempting to establish a region-wide health information network with the "3521 Project", which allows patient-related data to be accessed in all health facilities in the region [30]. In particular, the electronic patient file (EPF) and the electronic health record (EHR) are to become the standard. But the Corona crisis shows that standardization and interconnectivity require nation-wide standards which replace "island solutions" of self-developed hospital IT.

With the outbreak of the pandemic, the great challenge was to quickly provide reliable tests to detect the infection in large quantities. On January 16, the first batch of PCR test kits for the production of new coronavirus was delivered to provincial disease control centers, which is the direct reason for the rapid increase in the number of confirmed cases in recent days [31]. The duration of the test also reduced from 6 days at the beginning to within an hour until April 2020. This helped to block the spreading of the spreading of virus significantly.

Medical research institutions and pharmaceutical companies took on this task, for example, Beijing Genome Institute (BGI) handed over a first series of test kits on 26 January. By the end of February, BGI had delivered a total of 1.14 million test kits. The so-called Huoyan laboratory (火眼- Fire Eye) was set up and handed over in only five days in Wuhan [32]. Testing of new medications and technology could be realized faster in China than elsewhere, because Chinese are keen to experiment and some also help the common good, e.g. volunteers for vaccination testing are recruited among military staff.

The Wuhan Municipal Epidemic Prevention and Control Command took the 24-hour closure management measures. Citizens who had to go out e.g. for medical treatment had to download and install the "Wuhan Health Code". They needed to scan the code at the gate of the compound where they are living [33]. Later this method was adopted by other cities and regions across China for travel return to work and production, and access to public places and so on.

The Corona epidemic stimulated many companies to develop digital health support. For example, during the epidemic, China Mobile explored the innovative applications of $5 G$ and big data in the medical field. The telemedicine system facilitates the construction and operation of a national telemedicine collaborative platform, deploys "smart medical integration" solutions in more than 5,300 medical institutions across the country, strengthens the application of big data in epidemic surveillance, virus tracing, personnel tracking, etc [34].

Another company as example, JD Health launched a free online consultation platform since January $26^{\text {th }} 2020$ for "Preventing and Blocking New Coronavirus Pneumonia". It also launched the "Global Free Health Consultation Platform" at mid of March 2020 to provide free online consultation services to people around the world [35].

Results: It is unclear whether all (smaller) hospitals and clinics which dealt with Covid-19 patients were well standardized and available during the crisis. When the first chaos settled, governments and physicians emphasized the priority of registers and their online availability for infectious diseas- es and worked on improvements. Health and hygiene codes helped to contain the virus, as well as the implementation of laboratories and apps. Patient files and nation-wide aggregation help prevention, monitoring and care.

\section{Environment}

$R Q$ : Could environmental reasons have worsened the health status of people in Wuhan?

China is affected by the top global diseases as well as other countries are. Among those are heart disease, stroke, lung diseases, lower respiratory infection, Alzheimer's disease and other dementias, followed by trachea, bronchus and lung cancer ([36], based on 2016 data). Some of those diseases are known as preconditions which increase the deadly impact of the virus. For example, people with asthma and respiratory diseases have considerable difficulties and are among the most vulnerable persons in the Covid-19 crisis. A precondition of respiratory and lung diseases could be attributed to earlier mining, air pollution or smoking. Those potential factors are assessed in this chapter with regard to the situation in Wuhan.

The air pollution coming along with industrialization is a major problem in megacities. Reasons for the high level of particulate matter are, for example, the combustion of sulphur-containing lignite. Other causes of the high concentrations of particulate matter in the air are often illegal operation of filter-less small power plants, heating systems and fireplaces, and the inadequate storage of cement at construction sites. Lung cancer is a very common disease in brown coal areas and highly industrialized districts.

Wuhan is the birthplace of China's steel industry and draws on iron ore and coal from nearby mines. It is also a major manufacturing center for textiles, machinery, trucks and consumer products. In 2012, Hubei province counted as number eight in the highest $\mathrm{CO}_{2}$ emissions in China [37]. The city has high levees along the Yangtze protecting it from flooding and one of its most famous landmarks is the scenic but heavily polluted East Lake [38].

Encouraged by nationwide carbon emissions trading, $\mathrm{Hu}$ bei successfully promoted technological transformation, energy conservation and emission reduction [39]. At the same time, energy efficiency gains and structural upgrades contributed to major improvements of the air quality. In September 2016, Wuhan city started intensive measures to control air pollution [40]. They accelerated the completion of ultra-low emission transformation of coal-fired power units, and strictly controlled industrial coal combustion; expanded the no high-polluted-fuel burning zone and controlled the pollution of high-energy-consuming enterprises such as steel, cement, coking, and flat glass.

During the time of the outbreak, the weather in Hubei was already cold and damp. In Wuhan, the average temperature in January is 4 degrees (39.2 Fahrenheit), between 0 (night) and 7 (day) degrees Celsius (44.6 Fahrenheit) [41,42]. Laying in the Southern part of China, houses in Hubei province do not have regular heating systems. For months it is as cold in the house as it is outside. These chilly conditions regularly 
lead to colds and coughs. The hospitals are full of old people and children to get their symptoms treated. The "normality" of upper respiratory diseases during cold winter time might have weighted the major and his citizens in the belief that the nothing extraordinary would happen.

Results: Air pollution could not have been current major reason sincere cases of Covid-19 diseases in Wuhan. Lung problems and/or long-time exposure to fine dust in mines or factories could not be proven. This could only be analyzed through an analysis of previous patient files and eventually autopsy of the victims.

\section{Health insurance laws}

$R Q:$ Could legal issues like health insurances have an impact on the Corona crisis?

Health care services and the insurance coverage vary considerably depending on the type of employment and the environment in which people work. State administrations and companies generally have relatively good employer benefits in the event of illness. Depending on their rank, civil servants and higher ranks of huge companies occasionally enjoy the luxury of being treated as a "Very Important Person" (VIP) in good university hospitals. Medium-sized and small private enterprises (SMEs) are under strong economic competitive pressure and offer their employees far less generous social benefits than the large state-owned or private-sector model companies. The reforms created basic insurance for minor cases and there are also subsidies for serious illnesses, but around 40 percent of the costs must also be paid by the Chinese middle class itself [1].

The family thus remains the most important safety anchor. The risks are even bigger for migrant workers from other provinces which are unregistered: "The normal employment relationship in China is precarious" [43] and usually does not have adequate social security.

In the Covid-19 outbreak, several regulations were issued. One of the first patients, the seafood merchant Ms. Wei from Wuhan, first started to feel sick and went to a small local clinic to get some treatment. Other early cases also visited small, poorly resourced clinics and hospitals. The lack of money to finance chest computer tomography (CT) scans has caused huge problems during the first stage of the crisis [44].

As more and more people were getting sick and many could not afford the treatment, the National Healthcare Security Administration [45] issued a regulation for medical insurance system across China on 22 January that patients get timely treatment regardless of the cost, and designated medical institutions should treat patients regardless of medical insurance budget management regulations. To ensure that patients are treated on time, the central and local governments provided subsidies for the personal burden of medical expenses, on the basis of basic medical insurance, critical illness insurance, and medical assistance.

After a few days, another notice was issued from NHSA [46] "On Optimizing Medical Security Management Services and Promoting the Prevention and Control of Coronavirus". More items were included, for instance, carry out "non faceto-face work modes", support "long prescription for the con- venience of the people", extend the payment deadline. These regulations issued in January and February are supposed to lay foundations for the reform carried out on 5 March to solve the problem of uneven development of medical security and improve fair and appropriate treatment guarantee mechanism [47].

Results: Initially, the lack of full health insurance covering might have accelerated the transmission of the virus and delayed the arrival of severe cases in the hospital. Realizing the uneven development of medical security in different regions, the government adapted the procedures of hospital admittance and payment and strives to make sure that every person in China has basic health insurance.

\section{Discussion}

"Policy makers require foundational data that is timely accurate and disaggregated to design interventions that leave no one behind" [48]. But crisis situations are characterized by being chaotic and not completely transparent. This is an issue for all researchers now, including the World Health Organization (WHO). They are dependent on the reporting of national statistical offices but are lacking a complete oversight and data sets which would allow precise and definite answers for the many questions which are asked right now.

Finding the truth in times of a severe crisis is difficult. In order to find the best sources available and to get a well-balanced perception, reporting and analyzing, we formed a Sino-German team. We used Chinese official sources as well as reports from local press and media and international sources in order to balance potentially biased reporting, which cannot be excluded because of the specifics of the Chinese media which are part of the state's executive powers. A deeper analysis of the facts and the objectivity of the sources would require more time and more transparency of official data and internal processes. Embedded in the Western academic system, and trained in social and media science, we accessed and compared manifold sources, discussed their trustworthiness, intentions and perspectives and used such which could provide the best evidence possible in the given circumstances.

Following the PESTEL framework, we have chosen and discussed the most relevant factors which could relate to the developments after the outbreak of Covid-19 in China. We analyzed the healthcare related framework conditions which influenced the chaos in the beginning, the ameliorated procedures during the crisis and the innovative solutions which followed. The results are summarized at the end of each PESTEL sub-section and visualized in Figure 1. Other researchers may use our analyses for a better understanding of the health care system in China and their adaption during the crisis.

\section{Conclusion and Outlook}

The Communist Party's governance follows the dialectical thinking of the founder of the People's Republic Mao Zedong: Complex processes contain several contradictions. If the main contradiction is resolved, this will help solve all other problems $[49,50]$. On $18^{\text {th }}$ October 2017, Xi Jinping emphasized in the report of the $19^{\text {th }}$ National Congress that socialism with 
Chinese characteristics has entered a new era, and the main contradictions in our society have been transformed into the contradiction between the people's growing needs for a better life and unbalanced and inadequate development [51].

This contradiction has not been resolved yet. China knows they need more hospitals and already started massive building initiatives for new hospitals. More qualified physicians and hygiene officers were sent to communities and the idea of local practitioners in private practices, accredited by good universities and/or independent agencies, is being considered. Additionally, more interdisciplinarity in the medical education and solid trainings planned to be provided for the medical staff and collaboration between departments in hospitals should be reinforced. Further details have been provided for each of the factors discussed in the PESTEL model.

The Chinese culture is known for its flexibility in dealing with difficulties. Where there is a will, there is a way. If necessary, improvisation is used. The motto is to do research, to try things out on a small scale, and to continue if they were successful. China used several measures to contain the virus: Strict rules and controls, disinfection, fast data collection and tracking, combined with face recognition. Workers are called back to the factories, new hospitals are being constructed and public infrastructure is improved. At the same time, China's already high degree of digitalization continues to increase.

From January to February in 2020, the cumulative mobile Internet traffic in China reached 23.5 billion GB, a year-onyear increase of $44.2 \%$, which reflects the manifold online activities of people in confinement. The production index of information transmission, software and information technology services increased by $3.8 \%$ [14]. Digital working seems to be the new standard, not only China and for international businesses which practiced this for their cross-border collaboration, but also for small and medium sized companies, administrations, governments, universities and schools. This means that the fields of policy, economy, society, technology and environment and law - the whole PESTEL framework - will be changed fundamentally and, probably, irreversibly.

China is not the only one which will have learned their lessons: The crisis in different systems like China, Europe and the USA, shows that health care is not a business like any other. It cannot be managed like a commercial enterprise because it is part of the essential and strategic infrastructure of each country. Hospitals, for example, cannot be funded scarcely and organized like companies which maximize their profits. Hospitals, doctors and health care workers are indispensable and need a good and standard civil servant education and salary. At the same time, hospitals and manufacturers of health equipment should be seen as strategic suppliers which need sufficient capacities for providing the amount of materials required in crisis situations - not only for themselves but also for their partners.

The necessity of access to health facilities for all citizens gets very clear in an epidemic. The differences in the number of Corona victims in China and the USA, compared with Germany, shows that countries which do not provide full health insurance for their citizens are paying a hinger death toll.
In the US media, Chinese data are frequently doubted [52]. Hospitals, provinces and national statistical offices did a kind of "learning by doing" during the crisis; they changed their counting of corona victims 8 times during the crisis. Looking at Europe, this is no surprise. Italy also counts differently than Austria, Germany or the UK. Probably China had a similar problem: Non-consistent definitions of what a corona victim is and therefore non-consistent reporting. The whole world could learn from those shortcomings and come up with an international WHO standard to compare the developments. This would lead to a better transparency and more confidence and, at the same time, allow better support and refined confinement rules. Health is an international concern and thus needs international collaboration and mutual learning.

\section{Acknowledgements}

The authors are thankful for inputs from Dr. Gabriella Fuchs (Suzhou), Peter Tichauer (Qingdao) and Wenhen Sun (Munich) as well as for advice of Prof. Dr. Cathal McSwiney Brugha (UCD Dublin).

\section{References}

1. Daemmrich A (2013) The political economy of healthcare reform in China: Negotiating public and private. SpringerPlus.

2. Unschuld P (2013) Traditionelle chinesische Medizin (Traditional Chinese Medicine). CH Beck Publishing, Munich, 80-90.

3. Ulrike Reisach (2017) Das Gesundheitswesen in China. Strukturen, Akteure, Praxistipps. The Chinese Health Care System. Structures, Actors and Practical Advice. Medizinisch-wissenschaftliche Verlagsgesellschaft (Medical- Scientific Publishing House), Berlin.

4. Pillkahn U (2007) Trends und Szenarien als Werkzeuge zur Strategieentwicklung. Trends and scenarios as tools for strategy development. Der Weg in die unternehmerische Zukunft. Publicis Publishing, Erlangen/Germany.

5. People's Daily (2018) After the State Council's institutional reform, the first listed unit "Health and Planning Commission" transformed into "Health and Health Commission".

6. Buckley C, Myers SL (2020) As new virus spread, China's old habits delayed fight. The New York Times.

7. Chatkowski $P$, Author U, Bosch C (2017) Krankenhaustypen, Leistungsspektrum und Ausstattung (Types of hospitals, range of services and equipment). Das Gesundheitswesen in China. Strukturen, Akteure, Praxistipps. The Chinese Health Care System. Structures, Actors and Practical Advice. Medizinisch- wissenschaftliche Verlagsgesellschaft (Medical-Scientific Publishing House), Berlin, 43-54.

8. Organization for Economic Cooperation and Development (2020) Data for hospitals, etc.

9. A+Hospital (2020) List of Class III Grade A Hospitals in Wuhan.

10. Bian (2017) Über den Alltag in einer großen Shanghaier Klinik Interview mit einer Krankenhausmanagerin. About everyday life in a large Shanghai clinic - Interview with a hospital manager. Das Gesundheitswesen in China. Strukturen, Akteure, Praxistipps. The Chinese Health Care System. Structures, Actors and Practical Advice. Medizinisch-wissenschaftliche Verlagsgesellschaft (Medical- Scientific Publishing House), Berlin, 247-251. 
11. Dean J (2020) China publishes coronavirus patients autopsy results, infection sources determined. TASS.

12. https://cn.nytimes.com/china/20200203/china-coronavirus/ dual/

13. National Bureau of Statistics China (NBS) (2020) Statistics about the hospitals and medical staff in China.

14. ht t p://www.stats.gov.cn/tjgz/tjdt/202004/ t20200414_1738742.html

15. State Council (2020) Notice issued by the State Council to the National Health and Health Commission, the Ministry of Human Resources and Social Security, and the Ministry of Finance on measures to improve the working conditions of front-line medical staff and to care about the physical and mental health of medical staff.

16. Joe Hasell (2018) Table 1.B. in: World Economic Forum (WEF): Is income inequality rising around the world? Inequality in 1990 vs 2015. Our World in Data.

17. Zou S (2020) Autopsies reveal much about novel coronavirus. China Daily.

18. Wong P, Lin MCY, Jackson J (2019) Report: Best-performing cities in China 2019. Milken Institute.

19. Kao John (1993) The Worldwide Web of Chinese Business. Harvard Business Review, Cambridge, MA.

20. Liu GG, Huang JF (2013) Global hospital management survey China. Management in healthcare report. The US-China Business Council (USCBC) and Harvard Business School, Washington D.C./ Beijing/Shanghai.

21. Talhelm T, Zhang X, Oishi S, et al. (2014) Large-scale psychological differences within china explained by rice versus wheat agriculture. Science 344: 603-608.

22. (2020) Wuhan: On-line "Wuhan Health Code" citizens can scan for registration for special reasons. Xinhuanet.

23. Author, Bao Ngoc Van (2017) Grundlagen und Methoden der TCM im Vergleich zur traditionellen westlichen Medizin (Basics and methods of TCM, compared with Western medicine). Das Gesundheitswesen in China. Strukturen, Akteure, Praxistipps. The Chinese Health Care System. Structures, Actors and Practical Advice. Medizinisch-wissenschaftliche Verlagsgesellschaft (Medical-Scientific Publishing House), Berlin, 181-192.

24. (2019) 2018 China adult tobacco survey results released- smoking rate above 15 years old and over in China is declining. Chinese Center for Disease Control and Preventions.

25. Chang J, Ye D, Lv B, et al. (2017) Sale of antibiotics without a prescription at community pharmacies in urban China: a multicentre cross-sectional survey. Journal of Antimicrobial Chemotherapy 72: 1235-1242.

26. (2020) Coronavirus disease (COVID-19) advice for the public: Myth busters. World Health Organization.

27. (2020) Traditional medicine: Fighting it the Chinese way. The Economist, London, 42-43.

28. Wu JL (2020) Wuhan ten thousand banquet, which has been hotly debated by public opinion: From hundreds of banquets, it has been 20 years. Southern Metropolis Daily.

29. Grolle J (2020) Um jedes Leben (Fighting for each life). Der Spiegel Nr.

30. McDonald K (2015) Development of health IT an "unyielding principle" for China. Pulse+IT.
31. Tan P (2020) Rapid detection of new coronavirus, what new technologies are there. ScienceNet.

32. (2020) During the epidemic, 120 million students and students nationwide took classes. Xinhuanet.

33. (2020) Health and medical big data "national team" is formed! Lianren Health starts construction in Shanghai. Cn-healthcare.

34. https://www.cn-healthcare.com/articlewm/20200406/content-1101379.html

35. (2018) Global Health Observatory (GHO) data, top 10 causes of death. World Health Organization.

36. Shi M (2015) Chinas neue Mittelschichten. China's new middle class. Le Monde diplomatique: Atlas der Globalisierung (Atlas of globalization), Paris, 32-35

37. (2020) Trade Commissioner Service: Focus on Wuhan, China. Country and sector information. Government of Canada.

38. Zheng J, Mi Z, Coffman D, et al. (2019) Regional development and carbon emissions in China. Energy Economics 81: 25-36.

39. (2016) Notice of the municipal people's government on printing and distributing "strengthening measures for the prevention and control of air pollution in Wuhan". Wuhan city government.

40. https://data.cma.cn/en/?r=data/weatherBk

41. https://en.climate-data.org/asia/china/hubei/wuhan-2629/\#climate-table

42. https://en.genomics.cn/

43. Schucher G (2014) Chinas Arbeitsmärkte: Umbrüche, Risiken, Perspektiven. In: Müller-Hofstede C, Länderbericht China. Bundeszentrale für politische Bildung, Schriftenreihe Band 1501, Bonn, 703-738.

44. Page J, Fan WX, Khan N (2020) How it all started: China's early coronavirus missteps. The Wall Street Journal.

45. (2020) "Two Ensures" of the National Healthcare security Administration to respond to the epidemic. National Healthcare Security Administration.

46. (2020) Optimizing medical security management services and promoting the prevention and control of coronavirus. National Healthcare Security Administration.

47. (2020) Intensify the reform of the universal medical security system. Chinese Communist Party, State Council.

48. Misra A, Schmidt J, Harrison L (2020) Combating Covid-19 with data: What role for National Statistical Systems? OECD Policy Brief, Paris.

49. von Senger H (2015) KP will Paradies eines reichen China. The Communist Party wants the paradise of a rich China. Die Presse.

50. Surin K (2018) Mao's "On Contradiction," Mao-Hegel/MaoDeleuze. CLCWeb: Comparative Literature and Culture 20.3.

51. (2017) Xi Jinping pointed out that entering a new era of socialism with Chinese characteristics is a new historical orientation for China's development. Xinhuanet.

52. Campbell C, Gunia A (2020) China says it's beating Coronavirus. But can we believe its numbers? Time Magazine.

53. (2019) Healthcare personnel statistics - physicians. Eurostat.

54. (2018) EU population up to nearly 513 million. Eurostat.

55. (2020) Healthcare, length of hospital stay. Organization for Economic Cooperation and Development. 
56. (2020) Coronavirus: The world economy at risk, OECD Interim Report March 2020. Organization for Economic Cooperation and Development.
57. (2020) Beyond Containment: Health systems responses to COVID-19 in the OECD, OECD, Tackling Coronavirus (Covid-19) Contributing to a global effort.

DOI: $10.36959 / 577 / 490$ 